\title{
PENGUJIAN KEKUATAN TARIK DAN KEKUATAN LENTUR KOMPOSIT HIBRID PLASTIK BEKAS KEMASAN GELAS JENIS POLIPROPILENA/ SERBUK KAYU KELAPA TERMODIFIKASI/SERBUK SERAT KACA TIPE E
}

\author{
Silvia*, Castiqliana, Halimatuddahliana \\ Departemen Teknik Kimia, Fakultas Teknik, Universitas Sumatera Utara, \\ Jl. Almamater Kampus USU Medan 20155, Indonesia \\ *Email: silvia_ld@ymail.com
}

\begin{abstract}
Abstrak
Penelitian ini bertujuan untuk mengetahui pengaruh penambahan komposisi pengisi serbuk kayu kelapa termodifikasi dan penyerasi maleat anhidrida-g-polipropilena terhadap kekuatan tarik dan kekuatan lentur komposit hibrid. Modifikasi serbuk kayu kelapa juga dilakukan untuk mengurangi kepolarannya. Komposit hibrid dihasilkan dengan metoda pencampuran di dalam ekstruder. Komposisi serbuk serat kaca dan maleat anhidrida-g-polipropilena masing-masing yaitu 10 dan $2(\%$ b/b), sedangkan komposisi serbuk kayu kelapa termodifikasi divariasikan 10-40 $(\% \mathrm{~b} / \mathrm{b})$. Uji yang dilakukan yaitu uji tarik dan uji lentur. Hasil yang diperoleh menunjukkan bahwa penambahan serbuk kayu kelapa termodifikasi $20 \% \mathrm{~b} / \mathrm{b}$ menghasilkan sifat kekuatan tarik maksimum yaitu 24,1 MPa dan penambahan serbuk kayu kelapa termodifikasi $30 \% \mathrm{~b} / \mathrm{b}$ menghasilkan sifat kekuatan lentur maksimum yaitu 31,2 MPa serta peningkatan kedua sifat mekanik dengan menggunakan penyerasi maleat anhidrida-g-polipropilena.
\end{abstract}

Kata kunci: komposit hibrid, maleat anhidrida - g - polipropilena, serat kaca, serbuk kayu kelapa termodifikasi

\begin{abstract}
This study was aimed to investigate the effect of modified coconut wood flour and maleic anhydride-g-polypropylene addition in tensile strength and flexural strength of hybrid composite. Modification of coconut wood flour was also done to reduce the polarity. The hybrid composites were prepared by mixing method into an extruder. Glass Fiber Flour and maleic anhydride-gpolypropylene composition were made constant at $10 \mathrm{wt} . \%$ and $2 \mathrm{wt} \%$ respectively and modified coconut wood flour composition was varied from 10 - $40 \mathrm{wt} . \%$. Tensile test and flexural test were done. The results showed that addition of $20 \mathrm{wt} . \%$ modified coconut wood flour had given maximum tensile strength of 24,1 MPa and addition of $30 \mathrm{wt} . \%$ modified coconut wood flour had given maximum flexural strength of 31,2 MPa also inclination of both tensile and flexural strength of hybrid composite using maleic anhydride-g-polypropylene.
\end{abstract}

Keywords: hybrid composite, maleic anhydride - $g$ - polypropylene, glass fiber, modified coconut wood flour

\section{Pendahuluan}

Material komposit yang melibatkan dua atau lebih jenis pengisi dalam matriks disebut komposit hibrid [8]. Dengan komposit hibrid yang mengandung dua atau lebih pengisi, maka keunggulan dari suatu pengisi dapat melengkapi kelemahan pengisi lainnya [21]. Di Indonesia, produksi sampah plastik menduduki peringkat kedua penghasil sampah domestik yaitu sebesar 5,4 juta ton per tahun (14\% dari total produksi sampah di Indonesia).

Dalam upaya mengurangi limbah plastik tersebut, maka dalam penelitian ini digunakan polipropilena daur ulang yang berasal dari plastik bekas kemasan gelas sebagai matriks. Penggunaan polipropilena daur ulang dapat menurunkan sifat mekanik daripada komposit sehingga ditambahkan pengisi serat kaca untuk meningkatkan sifat mekaniknya [10]. Masalah lingkungan telah menjadi alasan utama untuk menggantikan penggunaan pengisi sintetik dengan pengisi alami yang bersifat lebih ramah lingkungan (biodegradable). Serbuk kayu dapat menjadi pilihan yang cocok karena biayanya relatif murah, memiliki densitas rendah [3], mudah terurai dan bersifat tidak abrasif selama proses $[8,14]$. 
Kombinasi antara serbuk kayu yang bersifat polar menyebabkan kesulitan untuk membentuk ikatan yang baik dengan polimer yang bersifat non-polar. Salah satu cara yang dapat dilakukan adalah memodifikasi serbuk kayu dengan mengurangi gugus hidroksilnya [18] sehingga mengurangi sifat kepolarannya. Pada penelitian ini juga digunakan MAPP, jenis penyerasi yang umum digunakan dalam komposit polimer serbuk kayu dan telah dikenal baik penggunaannya dalam komposit hibrid polipropilena berpengisi serat kaca [5].

Dalam penelitian ini akan dikaji sifat mekanik komposit yang meliputi uji tarik dan uji lentur.

\section{Teori}

Bahan komposit adalah bahan yang terdiri dari dua atau lebih fasa yang berbeda baik secara fisik ataupun kimia dan memiliki karateristik yang lebih unggul dari masingmasing komponen penyusunnya [16]. Polipropilena merupakan salah satu polimer yang paling tahan kondisi yang digunakan sebagai plastik dan serat [13]. Polipropilena adalah bahan termoplastik yang transparan, berwarna putih, mempunyai titik leleh 170$175^{\circ} \mathrm{C}[20]$.

Serat kaca merupakan bahan penguat yang paling umum digunakan dalam komposit matriks polimer karena biayanya rendah, sifat kekuatan dan ketahanan bahan kimia tinggi [5]. Serbuk kayu kelapa merupakan salah satu limbah industri pengolahan kayu seperti serbuk gergajian, sebetan, sisa kupasan [7]. Serbuk kayu kelapa juga sering dijadikan pengisi pada polimer termoplastik karena bersifat dapat diuraikan dan tidak abrasif bahkan setelah pengolahan [11]. Oleh karena itu, kedua jenis pengisi tersebut sering digunakan dan tak jarang juga dicampurkan pada suatu komposit. Penelitian tentang penggunaan serat kaca dan serbuk kayu kelapa sebagai pengisi komposit hybrid pernah dilakukan sebelumnya [10].

Namun, dalam pembuatan komposit akan terjadi kesulitan menggabungkan serat alami yang polar dengan matriks polipropilena dan serat kaca yang bersifat non-polar. Modifikasi kimia terhadap serat membantu mengurangi sifat kepolarannya [18], meningkatkan kekuatan partikel dan mengurangi penyerapan air [9]. Maleat anhidrida-g-polipropilena juga banyak digunakan sebagai penyerasi yang bertujuan meningkatkan keserasian antara matriks dengan pengisi dalam komposit.

Komposit yang telah dibuat akan diuji sifat - sifat mekanik yaitu uji tarik dan uji lentur. Kekuatan tarik merupakan parameter yang menunjukkan seberapa banyak tegangan berupa tarikan yang dapat diterima suatu material sebelum akhirnya putus [17]. Kekuatan lentur adalah suatu parameter yang menunjukkan kemampuan suatu material untuk menahan beban yang diberikan secara transversal diatasnya.

\section{Metodologi \\ Bahan dan Alat}

Bahan baku yang digunakan sebagai matriks adalah polipropilena daur ulang yang berasal dari Plastik Bekas Kemasan Gelas. Penyerasi yang digunakan adalah maleat anhidrida - g - polipropilena yang disintesa dengan menggunakan bahan baku berupa maleat anhidrida $\left(\mathrm{C}_{4} \mathrm{H}_{2} \mathrm{O}_{3}\right)$, xilena $\left(\mathrm{C}_{8} \mathrm{H}_{10}\right)$, polipropilena $\left(\left(\mathrm{C}_{3} \mathrm{H}_{6}\right)_{\mathrm{n}}\right)$, benzoil peroksida $\left(\mathrm{C}_{14} \mathrm{H}_{10} \mathrm{O}_{4}\right)$, aseton $\left(\mathrm{CH}_{3} \mathrm{COCH}_{3}\right)$, minyak goreng dan aquadest $\left(\mathrm{H}_{2} \mathrm{O}\right)$.

Sementara pengisi yang digunakan adalah serbuk serat kaca tipe - E dan serbuk kayu kelapa yang dimodifikasi dengan bahan natrium hidroksida $(\mathrm{NaOH}) 18 \%$, dan aquadest $\left(\mathrm{H}_{2} \mathrm{O}\right)$. Ukuran pengisi dan penyerasi yang digunakan adalah 100 mesh.

\section{Sintesa Maleat Anhidrida-g-Polipropilena}

Ditambahkan $1 \mathrm{~g}$ maleat anhidrida $90 \mathrm{ml}$ xilena dan $10 \mathrm{~g}$ polipropilena direfluks selama 20 menit pada temperatur $135^{\circ} \mathrm{C}$. Kemudian $0,1 \mathrm{~g}$ benzoil peroksida yang telah dilarutkan ke dalam $10 \mathrm{ml}$ xilena ditambahkan ke dalam campuran dan direaksikan selama 10 menit. Hasil reaksi dicuci dengan aseton untuk mengendapkan maleat anhidrida - g polipropilena, disaring dengan kertas saring dan dicuci dengan aquadest hingga $\mathrm{pH}$ nya netral. Selanjutnya dikeringkan dengan blower selama 24 jam.

\section{Proses Pembuatan Komposit Hibrid}

Komposit dilakukan dalam dua tahapan. Tahap pertama, Plastik Bekas Kemasan Gelas (PBKG), serbuk kayu kelapa termodifikasi (SKKT), serbuk serat kaca (SSK) dan penyerasi maleat anhidrida - $\mathrm{g}$ - polipropilena (MAPP) dicampur dengan komposisi tertentu, kemudian campuran tersebut dimasukkan ke dalam ekstruder. Temperatur proses yang digunakan adalah $180^{\circ} \mathrm{C}$ dengan kecepatan 50 putaran/menit. Pada tahap kedua, ekstrudat hasil ekstrusi dipotong-potong sehingga berbentuk butiran dan didinginkan dalam ember berisi air. Hasilnya lalu dikeringkan dengan suhu $105^{\circ} \mathrm{C}$ selama 24 jam sebelum dicetak pada mesin hot press yang bersuhu 180 ${ }^{\circ} \mathrm{C}$. 
Pengujian kekuatan tarik komposit menggunakan standar ASTM D-638 Tipe IV dengan mesin uji universal GOTECH AL7000M. Panjang alat ukur ditetapkan $72 \mathrm{~mm}$ dengan kecepatan $50 \mathrm{~mm} / \mathrm{menit}$ Mesin dihidupkan dan spesimen akan tertarik ke atas spesimen diamati sampai putus, dicatat tegangan maksimum dan regangannya. Pengujian kekuatan lentur dilakukan dengan mesin yang sama menggunakan standar ASTM D790. Kecepatan 5mm/menit digunakan. Mesin dihidupkan dan dicatat hasilnya.

Tabel 1 menunjukkan variasi komposisi komponen dalam komposit hibrid.

Tabel 1. Variasi Komposisi Komponen dalam Komposit Hibrid

\begin{tabular}{|c|c|c|c|c|}
\hline No & $\begin{array}{c}\text { PBKG } \\
(\%)\end{array}$ & $\begin{array}{c}\text { SKKT } \\
(\%)\end{array}$ & $\begin{array}{c}\text { SSK } \\
(\%)\end{array}$ & $\begin{array}{c}\text { MAPP } \\
(\%)\end{array}$ \\
\hline 1 & 80 & 10 & 10 & 0 \\
\hline 2 & 78 & 10 & 10 & 2 \\
\hline 3 & 70 & 20 & 10 & 0 \\
\hline 4 & 68 & 20 & 10 & 2 \\
\hline 5 & 60 & 30 & 10 & 0 \\
\hline 6 & 58 & 30 & 10 & 2 \\
\hline 7 & 50 & 40 & 10 & 0 \\
\hline 8 & 48 & 40 & 10 & 2 \\
\hline
\end{tabular}

\section{Hasil}

\section{Kekuatan Tarik (Tensile Strength)}

Gambar 1 menunjukkan hasil sifat kekuatan tarik pada komposit hibrid dimana nomor pada grafik merujuk kepada komposisi komponen yang dapat dilihat pada Tabel 1 . Kekuatan tarik merupakan parameter yang menunjukkan seberapa banyak tegangan berupa tarikan yang dapat diterima suatu material sebelum akhirnya putus. Kekuatan tarik dari komposit hibrid dipengaruhi oleh sifat pengisi, dispersi pengisi dan ikatan antarfasa diantara matriks dengan pengisi [19].

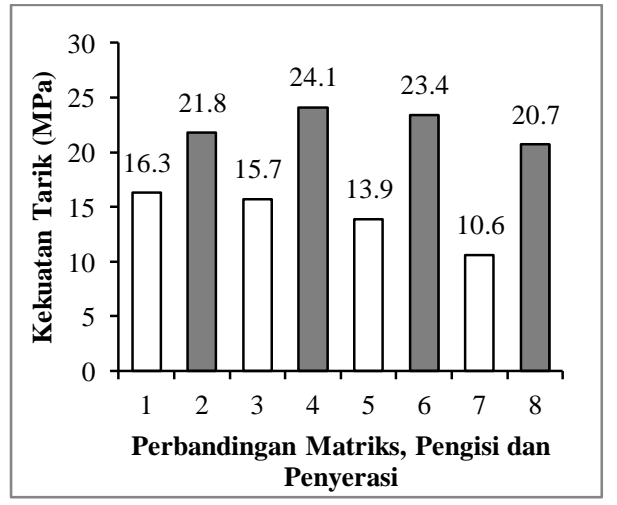

Gambar 1. Pengaruh Penambahan Komposisi SKKT dan MAPP Terhadap Kekuatan Tarik

\section{Komposit Hibrid}

Pada komposit hibrid yang tidak menggunakan penyerasi MAPP, terjadi penurunan sifat kekuatan tarik seiring dengan bertambahnya komposisi pengisi alami yang disebabkan karena ikatan interfasa yang buruk antara matriks dan pengisi sehingga hanya sedikit tegangan yang dapat dipindahkan dari matriks ke pengisi. Bertambahnya jumlah pengisi mengakibatkan perpindahan tegangan semakin sulit karena bertambahnya kontak antar pengisi [1].

Sebaliknya, peningkatan sifat kekuatan tarik terjadi pada komposit yang menggunakan MAPP dengan penambahan SKKT sampai $20 \%$ b/b. Hal ini disebabkan karena meningkatnya ikatan antarfasa antara matriks dan pengisi dengan adanya MAPP. Namun, seiring bertambahnya pengisi, kontak antar pengisi bertambah dan menyebabkan menurunnya kemampuan pengisi dalam memindahkan tegangan yang diperoleh dari matriks. Hasil ini juga diperoleh A. Karmakar dkk. [2] dan Arbelaiz dkk. [1] dimana terjadi peningkatan kekuatan tarik seiring bertambahnya komposisi pengisi dengan adanya penggunaan MAPP. Penggunaan MAPP memberikan efek nyata untuk meningkatkan hubungan interfasa yang baik antara matriks dan pengisi yang dapat meningkatkan sifat kekuatan tarik komposit.

\section{Kekuatan Lentur (Flexural Strength)}

Gambar 2 menunjukkan hasil sifat kekuatan lentur pada komposit hibrid dimana kode berupa angka pada grafik merujuk kepada komposisi komponen yang dapat dilihat pada Tabel 1.

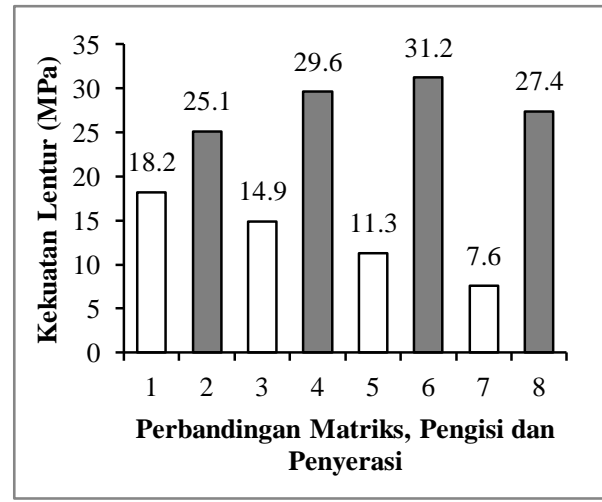

Gambar 2. Pengaruh Penambahan Komposisi SKKT dan MAPP Terhadap Kekuatan Lentur Komposit Hibrid

Kekuatan lentur adalah suatu parameter yang menunjukkan kemampuan suatu material untuk menahan beban yang diberikan secara 
transversal diatasnya. Pada komposit hibrid yang tidak menggunakan penyerasi MAPP, terjadi penurunan sifat kekuatan lentur seiring dengan bertambahnya komposisi pengisi alami. Hal ini disebabkan oleh ikatan interfasa yang buruk antara matriks dan pengisi yang mengakibatkan pemindahan tegangan dari matriks ke pengisi menjadi kurang efektif [12]. Bertambahnya jumlah pengisi mengakibatkan perpindahan tegangan semakin sulit karena bertambahnya kontak antar pengisi. Hasil ini juga diperoleh dari penelitian Marco Valente, dkk (2011) [12] bahwa penambahan jumlah pengisi dapat menurunkan kekuatan lentur komposit tanpa menggunakan penyerasi. Sebailknya, pada komposit yang menggunakan MAPP terjadi peningkatan kekuatan lentur seiring bertambahnya komposisi pengisi alami dikarenakan adanya ikatan yang baik antara matriks dan pengisi pada daerah interfasa sehingga material semakin kuat menahan beban yang diberikan [15]. Hasil yang sama juga diperoleh oleh Alireza (2014) [4], Nayak dan Mohanty (2010) [15] bahwa penambahan jumlah pengisi dapat meningkatkan kekuatan lentur komposit pada penggunaan penyerasi MAPP.

Kekuatan lentur biasanya berhubungan erat dengan nilai pemanjangan saat putus yang diperoleh pada uji kekuatan tarik. Nilai kekuatan lentur dan kekuatan tarik dapat memiliki nilai yang sama apabila material yang diujikan berada dalam keadaan homogen [3]. Suatu material dikatakan homogen apabila material tersebut memiliki sifat yang sama di setiap titik tanpa bergantung pada lokasi [6]. Pada kasus tertentu ada saatnya nilai kekuatan lentur dan kekuatan tarik memiliki nilai yang berlawanan. Pada uji kekuatan lentur, suatu material diberikan tegangan berupa tekanan yang berkonsentrasi pada suatu titik lokal tertentu, sehingga kekuatan lentur material akan bergantung pada jenis pengisi yang bersangkutan pada titik lokal tersebut, sedangkan pada uji kekuatan tarik, suatu material diberikan tegangan berupa tarikan yang berkonsentrasi pada seluruh material (termasuk pengisi) pada seluruh titik, sehingga patahan akan mulai terjadi ketika pengisi paling lemah mencapai titik kekuatan tarik maksimumnya [3].

\section{Kesimpulan}

Semakin bertambahnya jumlah pengisi SKKT pada komposit hibrid tanpa MAPP akan menurunkan sifat kekuatan tarik dan kekuatan lentur, sedangkan pada komposit hibrid dengan MAPP terlihat bahwa sifat kekuatan tarik dan kekuatan lentur yang dihasilkan lebih tinggi daripada yang tanpa MAPP. Nilai kekuatan tarik maksimum $(24,1$ $\mathrm{MPa}$ ) diperoleh dari sampel 7 dan nilai kekuatan lentur maksimum (31,2 $\mathrm{MPa})$ diperoleh dari sampel 9.

\section{Daftar Pustaka}

[1] A. Arbelaiz., B. Fernandez., J. A. Ramos., A. Retegi., R. Liano - Ponte., dan I. Mondragon, Mechanical Properties of Short Flax Fibre Bundle / Polypropylene Composites : Influence of Matrix / Fibre Modification, Fibre Content, Water Uptake and Recycling, Composites Science and Technology, 65 , hal 15821592, 2012.

[2] A. Karmarkar., S. S. Chauhan., J. M. Modak., dan M. Chanda., Mechanical Properties of Wood - Fiber Reinforced Polypropylene Composites : Effect of A Novel Compatibilizer With Isocyanate Functional Group, Composites Part A (38), hal 277-233, 2007.

[3] Ali I. Al - Mosawi., Moslem M. Ali., dan Salim J. Abbas., Using of Ansys Program to Calculate the Mechanical Properties of Advanced Fibers Reinforced Composite, The Iraqi Journal for Mechanical and Material Engineering, 12 (4) , 2012.

[4] Alireza Ashori., Amir Nourbakhsh., Ali Kazemi Tabrizi., Thermoplastic Hybrid Composites Using Bagasse, Corn Stalk and E - glass Fibers : Fabrication and Characterization, Polymer - Plastics Technology and Engineering 53:1-8. ISSN: 0360-2559, 2014.

[5] B. Mohebby., P. Fallah - Moghadam., A. R. Ghotbifar and S. Kazemi Najafi., Influence of Maleic - Anhydride Polypropylene (MAPP) on Wettability of Polypropylene / Wood Flour / Glass Fiber Hybrid Composites, Journal of Agricultural Science and Technology Vol 13, hal 877-884, 2011.

[6] H. Altenbach., J. Altenbach., dan W. Kissing., Mechanics of Composite Structural Elements, New York : Springer, hal 9, 2004.

[7] Jara, Rory., The Removal of Wood Components from Hardwood by Hot Water, Dissertation, The University of Maine, 2010.

[8] Khalil M. Jawaid, H.P.S., Khanam, P. Noorunnisa dan A. Abu Bakar., Hybrid Composites Made from Oil Palm Empty 
Fruit Bunches / Jute Fibres: Water Absorption, Thickness Swelling and Density Behaviours, J Polym Environ 19: 106-109, 2011.

[9] Livia Danyadi., Janoz Moczo., Bela Pukanszky., Effect of Various Surface Modifications of Wood Flour on the Properties of PP / Wood Composites, Elsevier. Composites: Part A 41, hal 199-206, 2010.

[10] M.A. Al-Maadeed., Ramazan Kahraman., P. Noorunnisa Khanam dan Nabil Madi, Date Palm Wood Flour / Glass Fibre Reinforced Hybrid Composites of Recycled Polypropylene: Mechanical and Thermal Properties, Materials and Design 42, hal 289-294, 2012.

[11] M. G Salemane dan A. S Luyt., Thermal and Mechanical Properties of Polypropylene - Wood Powder Composites, Journal of Applied Polymer Science, Vol. 100, hal 4173-4180, 2006.

[12] Marco Valente., Fabrizio Sarasini., Francesco Marra., Jacopo Tirilló., Giovanni Pulci, Hybrid Recycled Glass Fiber / Wood Flour Thermoplastic Composites: Manufacturing and Mechanical Characterization, Composites: Part A, 42, hal 649-657, 2011.

[13] Maulida, Campuran Limbah Padat organik dan Anorganik Pulp Sebagai Bahan Pengisi Mikrokomposit Termoplastik Poliolefin, Disertasi, Jurusan Matematika dan Ilmu Pengetahuan Alam, Universitas Sumatera Utara, Medan, 2010.

[14] Nachtigall, M.B., Graziela S. Cerveira dan Simone M. L. Rosa., New Polymeric - Coupling Agent for Polypropylene/ Wood - Flour Composites, Polymer Testing 26, hal 619-628, 2007.

[15] Nayak, Sanjay K dan Smita Mohanty, Sisal Glass Reinforced PP Hybrid Composites : Effect of MAPP on the Dynamic Mechanical and Thermal Properties, Journal of Reinforced Plastic and Composites, Vol 29 No. 10, 2010.

[16] Nurmawati, Pengaruh Waktu Tahan Sinter dan Fraksi Volume Penguat $\mathrm{Al}_{2} \mathrm{O}_{3}$ Terhadap Karakteristik Komposit Laminat Hibrid Al/SiC-Al/ $\mathrm{Al}_{2} \mathrm{O}_{3}$ Produk Metalurgi Serbuk, Skripsi, Fakultas Teknik Metalurgi dan Material, Universitas Indonesia, Depok, 2008.

[17] Paryanto Dwi Setyawan., Nasmi Herlina Sari dan Dewa Gede Pertama Putra, Pengaruh Orientasi dan Fraksi Volume
Serat Daun Nanas (Ananas comosus) Terhadap Kekuatan Tarik Komposit Polyester Tak Jenuh (UP), Dinamika Teknik Mesin, Vol 2 No.1, 2012.

[18] R.G.Raj., B.V Kokta dan C. Daneault., Effect of Chemical Treatment of Fibers on the Mechanical Properties of Polyethylene - Wood Fiber Composites, Journal of Adhesion Science and Technology, Vol 3 No.1, hal 55-64, 1989.

[19] Rimson Situmorang, Kualitas Papan Partikel dari Limbah Penggergajian Kayu, Skripsi, Jurusan Pertanian, Universitas Sumatera Utara, Medan, 2009.

[20] Sunariyo, Karakteristik Komposit Termoplastik Polipropilena dengan Serat Sabut Kelapa Sebagai Pengganti Bahan Palet Kayu, Tesis, Jurusan Ilmu Fisika, Universitas Sumatera Utara, Medan, 2008.

[21] Yi-Hua Cui dan Jie Tao, Fabrication and Mechanical Properties of Glass Fiber Reinforced Wood Plastic Hybrid Composites, Journal of Applied Polymer Science, Vol.112, 1250-1257, 2009. 